\title{
Avaliação clínica de anormalidades na diferenciação sexual em ovino: relato de caso
}

Thayane Jaeger ${ }^{1}$, Thainá Mara Schmitt ${ }^{1}$, Julian Michel Tschonka ${ }^{1}$, Dayane Priscila Vrisman ${ }^{1}$, Mariana Gonçalves Oliveira ${ }^{1}$, Denis Vinicius Bonato ${ }^{1}$, Anderson Gomes Carneiro ${ }^{1}$, Izabel Ferreira Albuquerque ${ }^{1}$, Luiz Paulo Mendes Ferreira ${ }^{1}$, Pedro Paulo Maia Teixeira ${ }^{1}$.

${ }^{1}$ Universidade Estadual do Centro-oeste, Campus CEDTEG, Departamento de Medicina Veterinária. Guarapuava, Paraná. [thainamara@hotmail.com].

ISSUE DOI: $10.3738 / 1982.2278 .1118$

O presente trabalho tem como objetivo analisar anormalidades na diferenciação sexual em um ovino de uma propriedade da colônia de Entre Rios (Guarapuava-PR). O paciente foi submetido a exames clínicos (físico e ultrassonográfico), não se tendo dados de histórico e anamnese. Pelo exame de dentição verificou-se que o paciente apresentava aproximadamente 7 anos, não existindo nenhuma alteração clínica aparente, além da ambiguidade sexual. Este ovino possuía comportamento, massa corpórea e conformação masculinizada, na genitália externa observaram a presença de um clitóris desenvolvido, quase a ponto de ser um pseudopênis, vulva e canal vaginal subdesenvolvidos. Na palpação se detectou duas massas maciças e ovais alojadas no úbere, constatando pelo exame ultrassonográfico que se tratava de testículos, sendo o esquerdo mais hipoplásico. Não foi possível chegar a um diagnóstico preciso da genitália interna pela avaliação ultrassonográfica transretal. Nesse contexto diagnosticou-se este paciente como um caso de intersexualidade, que é considerado uma alteração no desenvolvimento embrionário, e apresenta raríssima ocorrência para a espécie ovina. A alteração pode ser de origem genética, cromossômica ou hormonal, levando o mesmo indivíduo a apresentar características marcantes dos dois sexos, podendo se apresentar três possibilidades de diagnóstico clínico: hermafrodita verdadeiro, pseudo-hermafrodita e freemartin. O presente caso pode se tratar de um hermafrodita verdadeiro, no qual o animal apresenta ovários, testículos ou ovotestes, necessitando de avaliações de necropsia, laparotomia ou laparoscopia exploratória, para confirmar diagnóstico, já que não se confirmou a presença de ovários ao exame ultrassonográfico. $O$ freemartin é o resultado da modificação no desenvolvimento embrionário sexual de uma fêmea, em caso de partos gemelares (animais de sexos diferentes), no qual essa alteração ocorre através da passagem de fatores hormonais e/ou células, em que ocorre através da junção na vascularização da placenta destes embriões. Neste caso a fêmea pode ter passagem de células XY ou TDF (fator de diferenciação testicular) formando testículos no indivíduo. Devido ausência de histórico, não se sabe se esta é um caso de freemartin, já que não se possui dados da gestação, mas é uma das principais ocorrências de intersexo em ovelhas. Mais estudos são necessários para se estabelecer um diagnóstico clínico e genético, sendo que o paciente realizará avaliação de cariotipagem, 
avaliação laparoscópica exploratória, biópsia de porções do trato geniturinário e avaliação histopatológica, que serão realizados posteriormente para possibilitar descobrir qual intersexo se trata.

Palavras-chave: intersexo, ovelha, anormalidade de embrionária, diferenciação sexual, hermafrodita. 